\title{
Relationship between Loneliness and Mental Health of Boarders in Aba Tibetan and Qiang Autonomous Prefecture-The Moderating Effects of Resilience
}

\author{
Yining Wang \\ Department of computer science and technology \\ Southwest University of Science and Technology \\ Mianyang, China
}

\author{
Qian Xie \\ Department of psychology \\ Southwest University of Science and Technology \\ Mianyang, China
}

\author{
Xieping Chen \\ Department of psychology \\ Southwest University of Science and Technology \\ Mianyang, China
}

\begin{abstract}
Objective: to examine the boarder's moderating effects of resilience between mental health and loneliness in ethnic areas is to provide valid and scientific theories for improving the boarder's mental health situation. Methods: A total of six hundred and twenty-seven primary school students and junior school students in Song pan county of Aba Tibetan and Qiang Autonomous Prefecture were selected and assessed with the MMHI-Sixty for mental health, the CSL (children loneliness scale) for loneliness state, and the CD-RISC (Connor-Davidson Resilience Scale, (Connor-Davidson) for resilience. Results: in the sample, the CSL mean score was (three point five eight plus or minus zero point four six), the CD-RISC mean score was (three point two five plus or minus zero point five six), and the MMHI mean score was two point six five plus or minus zero point six three. The CLS scores were negatively correlated with the MMHI scores and the CDRISC scores ( $r$ value equals minus zero point three two seven, $P$ value is less than zero point zero one; $r$ equals minus zero point three eight five, both $p$ value are less than zero point zero one), the CD-RISC scores were positively correlated with the MMHI scores $(r$ value is zero one two one, $P$ value is less than zero point zero one). Hierarchy regression analysis shows that the CLS scores had a positive significant effect on MMHI scores (beta value is zero point two eight seven, $t$ value is six point one seven eight, $P$ value is less than zero point zero one), the CD-RISC scores had a negative significant effect on MMHI scores (beta value is minus zero point zero five eight, $t$ value is minus two point one double five, $P$ value is less than zero point zero five). And CD-RISC scores mediated the relationship between CLS scores and MMHI scores partially (The moderating effects was zero point zero two four). Conclusion: the result suggests that the boarders have some mental health and loneliness problems, and the resilience play a moderating role in loneliness and mental health.
\end{abstract}

Keywords-boarder; loneliness; resilience; mental health; moderating effect

\section{INTRODUCTION}

Aba prefecture is located in the northwest of Sichuan province, which is the second largest Tibetan area in Sichuan province and the main area of Qiang ethnic in china, and also the epicenter of Wenchuan earthquake in 2008. With the post-disaster reconstruction, the primary and middle boarding school gains a rapid development. Two years later, the number of boarding school reached 283, and the students add by 14 percent compared to pre-earthquake. There was a great improvement in hardware condition of boarding school, and over the 80 percent boarders can receive the living allowance from authorities. All the development and rebuilding after earthquake provide the students who are receiving compulsory education with substantial materials and the life security. With the study environment improving, the mental health situation of boarders has been aroused increasing number of attention in ethnic areas.

Relatively speaking, the boarding school is a special environment, which mainly reflect in the narrow life space, the place that until recently were deaf and dumb, and students always gather from much less with family, so it's inevitable to be lack of child-parent interaction. Therefore, the loneliness of boarders is more prominent than nonboarders.

Loneliness is a kind of negative emotional experience that may cause an adverse effect on individual mental health. However, there are various views on how does loneliness affect mental health, one think that the loneliness have a direct influence on mental health, the other believe that the loneliness can exert effect indirectly on mental health by other internal and external factors. The factors include that social support, optimism and resilience and so on.

An accepted definition of resilience is the state of being able to cope well with challenges after having encountered 
adversity. Previous study shows that the resilience plays a protective effect on mental health, in other words, the higher level of resilience the better mental health of individual. Meanwhile, other study finds that the resilience has a close negative association with loneliness, the higher level of resilience the lower level of loneliness. So the loneliness of boarders can exert a negative effect on mental health to some extent, but the resilience is a positive psychological character with overcoming adversity, which can play an advantageous role in mental health. Therefore, our study is based on the investigation of boarder's mental health situation in ethnic areas, and takes the resilience as a protective factor to examine it's the moderating effect between loneliness and mental health of boarders.

\section{METHODS}

\section{A. Participants and Sampling}

Firstly, methods with stratified cluster randomly sampling methods, Song pan country was chosen from the Aba Prefecture, secondly, four townships of Song pan country and one school from each selected township were selected as sampling areas, then four to nine grades were randomly from each school, a total of 13 classes with 627 students were selected to do the questionnaires. It have been got 511 valid questionnaires (valid return rate is $81.5 \%$ ), and made up of boys 249 (the proportion is $48.7 \%$ ) and girls 262(the proportion is $51.3 \%$ ), their average age is (13.18 1.36) years.

\section{B. Measurement}

The questionnaires, which consist of general social demographic characteristics, Children's Loneliness Scale (CLS), Connor-Davidson resilience scale (CD-RISC),

And MMHI-60.the self-design general social demographic characteristics such as gender, age, grade, caregiver etc., have been included in the survey.

The Children's Loneliness Scale, which was invented by professor Asher ,the scale consist of 24 items, 16 of which concerned loneliness, social adaption, and subjective assessment in status of their peer interaction. 10 items reflect loneliness, items represent non-loneliness), the others don't enter into the score. Some items keep reverse scoring. A 5point response scale is used in the report $(1=$ always be there, $5=$ it's not true, getting the higher score represent the higher level of loneliness), the scale internal consistency reliability of our study is 0.92 .
The CD-RISC scale was designed by psychologists Connor and Davidson in 2003.which contains 25 items including three dimensions: tenacity, strength and optimism that followed by domestic scholars who are Zhang Jianxin and Yu Xiaonan

Each item including five answers choices ranging from "Not at All True "to" Very Much Ture", scoring1, 2, 3, 4 or 5 , respectively. The higher scores the higher degree of resilience. The scale internal consistency reliability of our study is 0.89 .

The MMHI-60 scale was invented by domestic psychologist Wang Jishen, which was widely used to assess the mental health of middle school students in china, the scale consists of 60 items including ten content subscales, and each item was scored 1 for "never" and 5 for "yes", respectively. The higher the score is, the higher degree of mental health problem is, and the worse the children's mental health status is. The scale was classified into mild levels (scoring below 2), medium levels (between 2 and 3), heavier levels (between 3 and 4) and serious level (scoring is 5). The scale internal consistency reliability of our study is 0.94 .

Above all scales were revised properly under the condition of keeping the scale's original intention according to some feedback of pre-survey, so that it accord with the cognition of subjects.

\section{Procedure and Data Analysis}

The survey was conducted by 2 post-graduates who major in psychology and many teachers in November, 2016, all of who were trained in interviewing and administrating prior to investigation. All the participants were asked to complete the questionnaire independently and factually, if the children can't understand the meaning. They could hands up for help. After finishing the work above, the interviewers collected and checked all the questionnaires to make sure that there were no missing data or logical errors. And then the data were entered using Excel version 2007, finally importing all the statistics to SPSS version 17, calculating the general information, the relevance about variables, and regression coefficients. The two-tailed $\mathrm{P}$ value of $<0.05$ was considered to be significant.

\section{RESULTS}

\section{A. The Mental Health Status of the Boarders}

TABle I. The Detection Rate of Mental Health of Boarders in Aba Prefecture

\begin{tabular}{|c|c|c|c|c|c|c|c|c|c|c|c|}
\hline & Obsession & Stubborn & Hostility & $\begin{array}{l}\text { Interpersona } \\
\text { l-relationship }\end{array}$ & Depression & Anxiety & $\begin{array}{c}\text { Study- } \\
\text { pressure }\end{array}$ & $\begin{array}{c}\text { Maladjustme } \\
\text { nt }\end{array}$ & $\begin{array}{c}\text { Emotional - } \\
\text { imbalance }\end{array}$ & $\begin{array}{c}\text { Mental- } \\
\text { imbalance }\end{array}$ & Total \\
\hline Mild & 57.33 & 55.57 & 41.29 & 50.03 & 47.95 & 55.57 & 46.57 & 42.46 & 56.75 & 42.46 & 65.16 \\
\hline Medium & 29.15 & 18.20 & 15.45 & 16.24 & 14.09 & 19.76 & 26.22 & 15.06 & 17.81 & 8.81 & 9.79 \\
\hline Heavy & 2.35 & 1.76 & 2.74 & 1.76 & 2.15 & 4.31 & 4.11 & 0.98 & 1.37 & 0 & 0 \\
\hline Serious & 0 & 0 & 0 & 0 & 0 & 0 & 0 & 0 & 0 & 0 & 0 \\
\hline Total & 88.88 & 75.54 & 61.45 & 64.18 & 64.18 & 79.64 & 77.88 & 58.51 & 75.92 & 51.27 & 75.14 \\
\hline
\end{tabular}

In order to examine the general situation of border's mental health, we calculating the mental health problem detection rate in "Table I". It shows that there were $75.14 \%$ borders existing different degree psychological problems; all the factors of higher mental problem were obsession $(88.88 \%)$, and anxiety $(79.64 \%)$ and study pressure $(77.88 \%)$. 
It indicates that the mental health status of boarders in Aba prefecture isn't optimistic.

According to the independent-sample $\mathrm{T}$ test for the mental health of borders in Aba prefecture, their MMHI-60 synthesis scores were found to be significantly related to grades and age, and there is no remarkable difference in gender as followed by "Table II".In comparison with primary boarders, the junior boarders were more likely to be a better psychological status with higher degree level mental health $(\mathrm{P}<0.05)$. It is noteworthy that the primary boarders had a poorer MMHI-60 scores than junior boarders in maladjustment $(\mathrm{p}<0.001)$, while primary boarders showed a better MMHI-60 scores than junior boarders in study pressure scale $(\mathrm{p}<0.001)$.

\section{B. The Loneliness and Resilience Status of Boarders in Aba Prefecture}

The average CLS score was $(2.27 \pm 0.61)$, and then we do the independent-sample $\mathrm{T}$ test to examine the difference under the social-demographic characteristics, The study shows that there were no significant differences between boys and girls, primary boarders and junior boarders. $(\mathrm{t}=1.864, \mathrm{p}>0.05 ; \mathrm{t}=2.563, \mathrm{p}>0.05$ respectively). The CDRISC mean score was $(3.25 \pm 0.56)$, in order to explore the general situation of resilience, compared to the value 3 with single -sample $\mathrm{T}$ test, it indicates that the boarders own a higher degree level of resilience $(t=10.25, p<0.01)$, meanwhile the independent-sample $\mathrm{T}$ test for resilience in the social-demographic variables found that there was no remarkable difference in gender, the one-way ANOVA test shows that the resilience degree exist grade (age) difference ( $p<0.01$, respectively), it means the higher grade the better status of resilience. As the individual grow older, the capacities which overcome adversity and renew the normal psychological function were stronger. The "Table II" shows these things.

TABLE II. THE INDEPENDENT-SAMPLE T-TEST OF MMHI IN DIFFERENT DEMOGRAPHIC CHARACTERISTICS (M \pm SD) (N=511)

\begin{tabular}{|c|c|c|c|c|c|c|c|c|c|c|c|c|c|}
\hline Group & & $\begin{array}{c}\text { Valu } \\
\text { e }\end{array}$ & $\begin{array}{c}\text { Obsess } \\
\text { ion }\end{array}$ & $\begin{array}{c}\text { Stubbor } \\
n\end{array}$ & $\begin{array}{c}\text { Hostili } \\
\text { ty }\end{array}$ & $\begin{array}{c}\text { Interpersonal-- } \\
\text { relationship }\end{array}$ & $\begin{array}{l}\text { Depres } \\
\text { sion }\end{array}$ & $\begin{array}{c}\text { Anxiet } \\
\mathbf{y}\end{array}$ & $\begin{array}{c}\text { Study- } \\
\text { pressure }\end{array}$ & $\begin{array}{c}\text { Malad } \\
\text { justme } \\
\text { nt }\end{array}$ & $\begin{array}{l}\text { Emotional- } \\
\text { imbalance }\end{array}$ & $\begin{array}{c}\text { Mental- } \\
\text { imbalanc } \\
\text { e }\end{array}$ & Total \\
\hline \multirow[t]{6}{*}{ Gender } & Male & $M$ & 2.61 & 2.41 & 2.27 & 2.12 & 2.18 & 2.44 & 2.63 & 2.48 & 2.11 & 2.00 & 2.31 \\
\hline & & $S D$ & 0.59 & 0.73 & 0.74 & 0.66 & 0.68 & 0.76 & 0.84 & 0.71 & 0.67 & 0.62 & 0.50 \\
\hline & Female & & 2.65 & 2.40 & 2.27 & 2.35 & 2.25 & 2.52 & 2.50 & 2.11 & 2.37 & 2.02 & 2.38 \\
\hline & & & 0.60 & 0.60 & 0.78 & 0.67 & 0.67 & 0.72 & 0.75 & 0.67 & 0.61 & 0.61 & 0.45 \\
\hline & T value & & -0.74 & 0.28 & 0.09 & -2.23 & -1.08 & -1.20 & -1.73 & 1.21 & 0.59 & -0.34 & -0.19 \\
\hline & P value & & $>0.05$ & $>0.05$ & $>0.05$ & $>0.05$ & $>0.05$ & $>0.05$ & $>0.05$ & $>0.05$ & $>0.05$ & $>0.05$ & $>0.05$ \\
\hline \multirow[t]{6}{*}{ Grade } & $\begin{array}{c}\text { Primar } \\
y\end{array}$ & $M$ & 2.58 & 2.43 & 2.17 & 2.17 & 2.13 & 2.38 & 2.28 & 2.19 & 2.36 & 1.98 & 2.30 \\
\hline & & $S D$ & 0.53 & 0.74 & 0.63 & 0.58 & 0.63 & 0.62 & 0.74 & 0.69 & 0.55 & 0.53 & 0.41 \\
\hline & Junior & & 2.65 & 2.39 & 2.29 & 2.22 & 2.24 & 2.51 & 2.64 & 1.99 & 2.40 & 2.07 & 2.38 \\
\hline & & & 0.61 & 0.64 & 0.79 & 0.68 & 0.68 & 0.77 & 0.79 & 0.68 & 0.66 & 0.63 & 0.48 \\
\hline & T value & & -1.00 & 0.55 & -1.52 & -1.28 & -1.57 & -1.56 & -4.33 & 2.70 & -0.64 & -1.61 & -2.05 \\
\hline & Pvalue & & $>0.05$ & $>0.05$ & $>0.05$ & $>0.05$ & $>0.05$ & $>0.05$ & $<0.001$ & $<0.001$ & $>0.05$ & $>0.05$ & $<0.05$ \\
\hline
\end{tabular}

C. The Association of Three Variables (Loneliness, Resilience, Mental health)

The correlative analysis among three variables seen as the "Table III", it shows that the CLS scores were negatively correlated with the MMHI scores and the CD-RISC scores $(\mathrm{r}=-0.327, \mathrm{P}<0.001 ; \mathrm{r}=-0.385, \mathrm{p}<0.01)$, the CD-RISC scores were positively correlated with the MMHI $\operatorname{scores}(\mathrm{r}=0.121$, $\mathrm{P}<0.01)$.

TABLE III. ThE ASSOCIATION OF THREE VARIABLES(N=511)

\begin{tabular}{|c|l|l|l|}
\hline & \multicolumn{1}{|c|}{ Loneliness } & Resilience & Mental health \\
\hline Loneliness & 1 & & \\
\hline Resilience & $-0.391 * *$ & 1 & \\
\hline Mental health & $0.327 * *$ & $-0.132^{* *}$ & 1 \\
\hline \multicolumn{3}{|c|}{${ }^{\text {a. }}$ Note:* means $\mathrm{p}<0.05, * *$ means $\mathrm{p}<0.01$} \\
\hline
\end{tabular}

D. Examination of Resilience's Moderating Effect Between Loneliness and Mental Health of Boarders in Aba Prefecture $(n=511)$
TABLE IV. THE HIERARCHY REGRESSION ANALYSIS OF THE BOARDER's LONELINESS, RESILIENCE AND MENTAL HEALTH(N=511)

\begin{tabular}{|c|c|c|c|c|}
\hline \multicolumn{2}{|r|}{ Variables } & \multicolumn{3}{|c|}{ MMHI } \\
\hline & & M1 & M2 & M3 \\
\hline First step & Gender & 0.05 & 0.09 & 0.08 \\
\hline & Grade & 0.07 & 0.12 & 0.11 \\
\hline Second & Loneliness & & $0.287^{\text {**** }}$ & $0.288^{\text {**** }}$ \\
\hline & Resilience & & -0.058 & -0.049 \\
\hline Third step & Loneliness $\times$ Resilience & & & 0.154 \\
\hline & $\mathrm{R}^{2}$ & & 0.073 & 0.087 \\
\hline & Adjusted $\mathrm{R}^{2}$ & & 0.069 & 0.082 \\
\hline & $\Delta \mathrm{R}^{2}$ & & 0.073 & 0.024 \\
\hline & $\mathrm{F}$ & & 19.823 & $15.997^{\text {**** }}$ \\
\hline & $\Delta \mathrm{F}$ & & 19.823 & $7.808^{*}$ \\
\hline
\end{tabular}

The hierarchy regression model revealed that MMHI-60 of the boarders were significantly positively associated with their grade $(\beta=0.12, \mathrm{p}<0.05)$ in "Table IV". CLS scores had a positive significant effect on MMHI scores and the regression coefficient was $(\beta=0.287, \mathrm{t}=6.178, \mathrm{P}<0.01)$, the CD-RISC scores had a negative significant effect on MMHI scores and the regression coefficient was $(\beta=0.154, p<0.001)$, CLS and CD-RISC scores had a remarkable interaction 
effect on MMHI scores $(\beta=-0.058, \mathrm{t}=-2.155, \mathrm{P}<0.05)$. CDRISC scores mediated the relationship between CSL scores and MMHI scores partially (The moderating effects was 0.024 .

To be more explicitly examine the moderating effect of resilience, according to the scores of resilience, we divided the boarders into two groups whose resilience scores, the one is a group of high degree resilience (the scores that above a standard deviation of the mean value) another group of low degree resilience (the scores lower than a standard deviation of the mean value). The subjects of loneliness scores were also divided into two groups in the same way. As we can see in the "Fig. 1": The boarders are faced with high degree of loneliness, the boarders with low degree of resilience would be affected distinctly, and it means the degree of mental health would be declined obviously. However, as for the group with high degree resilience when they are faced with high degree loneliness, the downward slope of mental health is gentle. It indicates that the resilience function definitely play a moderating role in the relationship between loneliness and mental health, in other words, the resilience is an internal protective factor for the negative effect relationship between loneliness and mental health.

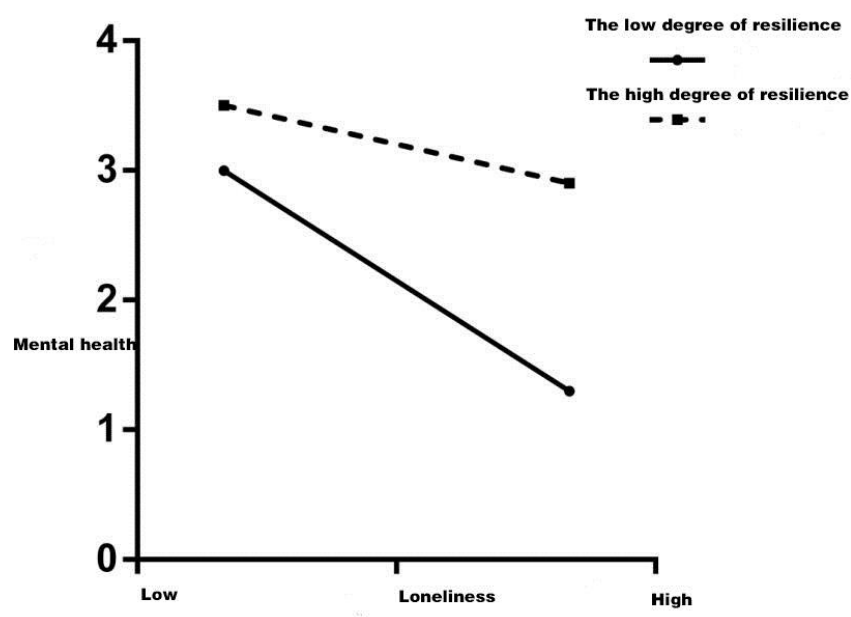

Fig. 1. The sketch map of moderating effect of resilience.

\section{DISCUSSION}

This study is the first one to examine the resilience's moderating effect between loneliness and mental health of boarders in Aba Tibetan and Qiang Autonomous Prefecture. Our finding shows that the detection rate of boarders' mental health is higher relatively, the mental health status isn't optimistic .the finding in this study corresponds to the result reported in related study about the boarder's mental health in The Tibetan autonomous prefecture of Qinghai. Besides, the loneliness level in this study didn't differ significantly in social-demographic variables. This is probable due to the specific natural geographical condition and environment in Aba prefecture, it covers a vast territory with a sparse population and the remote distance between school and home, leading to the long term of boarding life with the distant emotional connection, the less chance of communicating with parents and the low quality of inter action between family and children. All those contributed to the alienation in emotional interaction. Especially for the adolescent period, the individual are of rebellion character. The mutual lack of understanding is easily devoted to the tension in parent-child relationship. The developmental psychology believes that individual development abide by the principle of sequential. First, the individual should obtain the sense of security, love and affection of family and so on natural properties. And then the social properties will be acquired physical and mental development. On the other hand, it maybe lack of cognition about mental health problem, they pay less attention to the psychological situation. Besides the children probably don't know how to counseling psychological problem .Meanwhile, taking the obstacles and dilemmas in implement primary and middle school students psychological education in ethnic areas into consideration, So that it isn't establish a system of mental health education program.

Our findings indicates that the mental health level of primary boarders is significantly lower than that of middle boarders, it means that as age increased, the average MMHI60 scores of the boarders were remarkably declined, which was accordance with the other studies focus on boarders and left-behind children. On the one hand, the primary boarders' scores of maladjustment is higher than that of middle boarders, The longer time of boarding life and physical and mental development is growing as age increased, they are in social development stage to formulate the quality of cooperation, self-discipline and freedom. So they own a relatively psychological environment to accommodation in school. However, the study pressure scores of middle boarders' are higher than primary boarders. Analysis the reasons for this findings, it probably due to under the traditional nation's oriented system, the middle school student have to be faced with more powerful enrollment pressure and fierce competition .Besides, the boarders in Aba prefecture have a long for walking out mountain to look for outside world and broaden their horizons, perhaps, this is the reliable way to help them realize their dream, studying hard is an invisible pressure for them. But for primary boarders, they still have not built this cognition and awareness, so their study pressure status is better. What else, because of the high altitude and climate in Aba prefecture and the sports facilities isn't enough in schools, directly related to the effect of the physical and mental psychological training of boarders who are with high study pressure and other mental health problems; they may need a space and time to release their pressure and bad mood.

Our findings also shows that the scores of loneliness is positively related with mental health scores and the standardized regression coefficient $(\beta=-0.287)$, which was confronted with the previous studies about boarders, the research achievements shows that the interpersonal communication, emotional interaction, study pressure and loneliness etc., are significantly associated with mental health, in means the emotional experience of loneliness is lower, the higher level of mental health. In fact, loneliness exerts an adverse effect on mental health, which is ultimately 
corresponds with the level of resilience. The high level of resilience, the better status of mental health, and the resilience has a positive predict effect on mental health. The boarders' loneliness experience is not only the dangerous factor for the level of mental health, but in this psychological process it might provocative the inner potential ability to temper character and willpower, so that they can formulate higher level of resilience to some extent for the protective factors when they encounter some negative life events.

We founded that the resilience level of boarders were in a good situation. The probable reason is that the bad weather and natural disaster such as earthquake, mud-rock flow and landslide etc. That disaster experience makes them stronger and strength to $\mathrm{f}$ be faced with difficulties and obstacles, their resilience level got improved a lot. What's more, our finding shows that resilience play a moderating effect on loneliness and mental health, the higher degree of resilience could compensate for the negative effect which was brought by loneliness on level of mental health .which was accordance with the previous research. The loneliness belongs to a internal adverse factor in the process of developing a better mental health level. It exert a significantly negative predict effect on mental health. Meanwhile, the resilience could alleviate the negative effect when the boarders are faced with high level loneliness to protect the mental health of boarders from being suffered When the psychology education is being implemented, we should not only make concentration on the disadvantage circumstance and adverse outcome, but also we should be good at discovering the inner protective factors to improve the mental health status. From the positive psychology perspective, we should change the belief that the boarders belong to the social disadvantaged group, and maybe they get a better psychological development.

Meanwhile, under the different degree of resilience, the changeable relationship between loneliness and mental health indicates that the resilience's moderating effect on loneliness and between don't show the qualitative change but the alteration of volume, it's also associated with the previous research. Regardless of the level of resilience, the increasing level of loneliness make the mental health degree declined. With the improvement of resilience's level the loneliness's impulse impact upon mental health would be tend to weaken. So when the boarders are faced with high level of loneliness, it's more of great importance on the protective effect that between the high level of resilience and mental health.

\section{CONCLUSION}

In summary, our investigation provides preliminary evidence that the mental health status of the boarders isn't optimistic, therefore taking preventive actions to improve the level of mental health is necessary. Our findings have implications for preventive action to improve the mental health of degree. The government should fasten the step to overcome some obstacles and adversity to establish the psychological education system and program, the local schools and teachers also should widen the horizon about the psychological profession. The local government and school could exploit the school-curriculum and the curriculum resource should attach importance upon the integration of local ethnic specific culture. For example, the school could properly increase the communication chance for different grades boarders to exert more positive effect mutually to some degree. However, there are several limitations in our study .Firstly, we focused on boarders in Aba prefecture ,so the lack of comparative study with non-boarders still on the air .Secondly, our study pay attention to the cross-sectional study, the lack of follow-up study .Finally, the research contents we maybe pay less attention to the internal mechanisms about loneliness, mental health and resilience .above all problems, we have a long for the following study could be settled and get more improvement to provide the psychological education with more scientific and valid theoretical and practical suggestions.

\section{REFERENCE}

[1] http://scnews.newssc.org/system/2010/10/15/012930061.html.sichuan

[2] Fang H. (2014). The effect on loneliness in middle school period when students live a boarding life in primary school period. (Doctoral dissertation, Central China Normal University)

[3] Guo ZH, Han ZH, Shi YT, Shangguan QY, Guoyu PG,\& Xin L (2014). The rural left-behind children's loneliness and mental health investigation study in Baoji city. Chinese Children's Mental health Magazine, 22(6), 630-632

[4] Feng CX.. (2012). The relationship study on loneliness and mental health of rural middle school students in Jin Zhong city. The Academic Journal of Jin zhong university, 29(1), 93-95.

[5] Chen XF, \& Shi K. (2008). The effect of loneliness and perceived social supprot on mental health of undergraduate .Chinese Journal of Clinical Psychology,16(5), 534-536.

[6] Guo XD, Li YQ, Wang, LN ,\& Shen JL. (2006).The moderating effect of social support between life events and mental health Chinese Journal of Clinical Psychology, 14(5), 530-531.

[7] Masten A S, Coatsworth J D. The development of competence in favorable and unfavorable environments lessons form research on successful children. American Psychologist, 1998, 56:205 - 220

[8] Wang YH. (2010). Studying the left -behind children's social support net from the perspective of resilience. Educational Research Monthly(10), 6-7.

[9] Zhou YH, Lv CF, \& Xu FH. (2013). The study between resilience and mental health in left-behind children. Chinese Journal of Special Education(10)

[10] Rutter, M. (1993). Resilience: some conceptual considerations. Journal of Adolescent Health Official Publication of the Society for Adolescent Medicine, 14(8), 690-6.

[11] Dong ZS, \&Zhang DJ. (2013). The relationship study between loneliness and resilience of left-behind children in ethnic areas. Chinese Journal of School Health 34(7), 827-829

[12] Connor, K. M., \& Jonathan, R. T. D. M. D. (2003). Development of a new resilience scale: the connor- davidson resilience scale (cdrisc).Depression and Anxiety, 18(2), 76.

[13] Martinez, A. A., Zecchini, V., \& Brennan, K. (2002). Clsindependent notch signalling: a checkpoint in cell fate decisions during development?.Current Opinion in Genetics \& Development, 12(5), 524-533.

[14] Wang JS, Li Y, (1997).the compontent and standardization of mental health scale of chinese middle school students. Science of Social Psychology(4), 21-25

[15] Ma CF. (2017). The relationship between mental health and social support of boarders in Qinghai Tibetan areas .Ethnic Education Study(1). 
[16] Jiang SK, \&Liang JL. (2015). The investigation study of mental health status between boarders and non-boarders. The Academic Journal of Xiang Y yang Professional Technology College(2), 121125

[17] Li KY. (2014). The relationship study about loneliness mental health and social support of middle boarders. (Doctoral dissertation, Chong Qing Normal University).

[18] Yang XJ. (2010). The relationship study between school adjustment and mental health of middle boarders in Yan bian areas. (Doctoral dissertation, Yan bian university)

[19] Wright, M. O., Masten, A. S., \& Narayan, A. J. (2013). Resilience Processes in Development: Four Waves of Research on Positive Adaptation in the Context of Adversity. Handbook of Resilience in Children.

[20] Rutter, M. (1994). Rutter m. resilience: some conceptual considerations .Journal of Adolescent Health, 14(8), 626-31, 690-6

[21] Song GW, He YF, Ding N, Lv LC ,\&Zhou K.. (2013).The relationship about mental health subjective well-being and resilience of the middle school student who were left-behind. Chinese Journal of Special Education(2), 87-91.

[22] Song GW, Luo F, \&Zhou FF. (2014). The relationship research on social support resilience and mental health of gifted students and students with learning difficulties. Chinese Journal of Special Education(3),55-62 